\title{
IL-1 blockade as a novel approach to treatment of hyperzincemia and hypercalprotectinemia, a possible new autoinflammatory syndrome
}

\author{
Geraldina Lionetti ${ }^{1 *}$, Jonathan A Bernstein ${ }^{1}$, Dirk Holzinger ${ }^{3}$, Michael Jeng $^{1}$, Johannes Roth², Neda Zadeh${ }^{1}$, \\ Joyce Hsu'
}

From 2011 Pediatric Rheumatology Symposium sponsored by the American College of Rheumatology Miami, FL, USA. 2-5 June 2011

\section{Purpose}

To describe a possible new autoinflammatory syndrome in a patient with hyperzincemia and hypercalprotectinemia with significant improvement upon initiation of anakinra.

\section{Methods}

We describe a patient initially evaluated at 10 months of age for gross developmental delay, failure to thrive, splenomegaly, and microcytic anemia. Physical exam was significant for weight $<3$ rd percentile, splenomegaly (down $5 \mathrm{~cm}$ ), and head lag. Initial laboratories revealed microcytic anemia (hemoglobin $8.7 \mathrm{~g} / \mathrm{dL}$ ); elevated platelets 499 $\mathrm{K} / \mathrm{uL}, \mathrm{C}$-reactive protein $23.2 \mathrm{mg} / \mathrm{dL}(<0.2)$ and erythrocyte sedimentation rate $120 \mathrm{~mm} / \mathrm{h}(0-10)$. Radiographs showed Erlenmeyer flask deformities of the femurs. Workup for lysosomal storage disorders, oncologic processes, and infections were negative. Genetic testing of known mutations in FAS, CIAS1, ELA2, LPIN2, MVK, PSTPIP1, and TNFRSF1A were negative. Immunoglobulins were elevated with normal $\mathrm{T}$ and $\mathrm{B}$ cells. On further workup for failure to thrive, a plasma zinc level was found elevated at $532 \mathrm{mcg} / \mathrm{dL}(60-120)$. Due to his persistently inflamed state, there was concern for hyperzincemia related to hypercalprotectinemia. Calprotectin level, measured by enzyme-linked immunosorbent assay, was elevated: $428,300 \mathrm{ng} / \mathrm{mL}(<420)$. On the basis of these findings the diagnosis of hyperzincemia associated with hypercalprotectinemia was made (OMIM 194470). Additionally, the patient's workup has revealed the following mutations with unknown clinical significance: a

Stanford University, Palo Alto, CA, USA

Full list of author information is available at the end of the article heterozygous variant in the $M E F V$ gene (T577A), a hemizygous duplication of exons 61-79 of the dystrophin gene (CPK normal), and a maternally inherited microduplication at Xp21.2. Colchicine was started due to the $M E F V$ gene mutation with little to no improvement. Based on calprotectin's role in inflammation, and possible link to IL-1, anakinra was initiated.

\section{Results}

Four weeks after initiation of anakinra, our patient's splenomegaly resolved, and inflammatory markers decreased significantly with improvement in his anemia.

\section{Conclusion}

Approximately 8 patients with the diagnosis of hyperzincemia and hypercalprotectinemia have been described in the literature thus far, with the specific genetic cause still unknown. Consistent clinical findings are hepatosplenomegaly, anemia, elevated inflammatory markers, as well as characteristic elevations of serum zinc and calprotectin. Treatments have included corticosteroids and calcineurin inhibitors with little or no sustained benefit. We initiated anakinra due to the role of calprotectin in the inflammatory response. Calprotectin, a complex of S100A8 and S100A9 proteins, is in the family of calcium-binding proteins expressed by activated neutrophils and monocytes. It is unique in that it contains zinc-binding domains and leads to dysregulation of zinc levels when elevated. It is believed to be involved in antimicrobial activities and has a regulatory role in inflammatory reactions. Pro-inflammatory cytokines such as IL-1 have been shown to increase calprotectin levels. This is the first case report to show the use of an IL-1 inhibitor in a patient with hyperzincemia and hypercalprotectinemia. 


\section{Disclosure}

Geraldina Lionetti: None; Jonathan A. Bernstein: None; Dirk Holzinger: None; Michael Jeng: None; Johannes Roth: None; Neda Zadeh: None; Joyce Hsu: None.

\section{Author details}

${ }^{1}$ Stanford University, Palo Alto, CA, USA. ${ }^{2}$ University of Muenster, Muenster, Germany. ${ }^{3}$.

Published: 13 July 2012

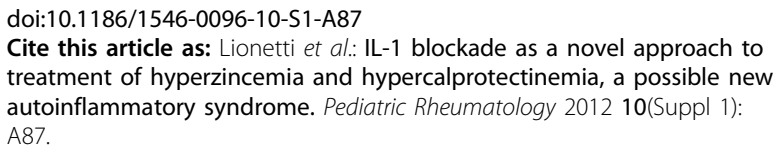

Submit your next manuscript to BioMed Central and take full advantage of:

- Convenient online submission

- Thorough peer review

- No space constraints or color figure charges

- Immediate publication on acceptance

- Inclusion in PubMed, CAS, Scopus and Google Scholar

- Research which is freely available for redistribution 